\title{
Cerebral Perfusion Is Perturbed by Preterm Birth and Brain Injury
}

\author{
(DE.S. Mahdi, (D) M. Bouyssi-Kobar, (D) M.B. Jacobs, (D). Murnick, (DT. Chang, and (D). Limperopoulos
} O-

\begin{abstract}
BACKGROUND AND PURPOSE: Early disturbances in systemic and cerebral hemodynamics are thought to mediate prematurity-related brain injury. However, the extent to which CBF is perturbed by preterm birth is unknown. Our aim was to compare global and regional CBF in preterm infants with and without brain injury on conventional MR imaging using arterial spin-labeling during the third trimester of ex utero life and to examine the relationship between clinical risk factors and CBF.
\end{abstract}

MATERIALS AND METHODS: We prospectively enrolled preterm infants younger than 32 weeks' gestational age and $<1500 \mathrm{~g}$ and performed arterial spin-labeling MR imaging studies. Global and regional CBF in the cerebral cortex, thalami, pons, and cerebellum was quantified. Preterm infants were stratified into those with and without structural brain injury. We further categorized preterm infants by brain injury severity: moderate-severe and mild.

RESULTS: We studied 78 preterm infants: 31 without brain injury and 47 with brain injury ( 29 with mild and 18 with moderate-severe injury). Global CBF showed a borderline significant increase with increasing gestational age at birth $(P=.05)$ and trended lower in preterm infants with brain injury $(P=.07)$. Similarly, regional CBF was significantly lower in the right thalamus and midpons $(P<.05)$ and trended lower in the midtemporal, left thalamus, and anterior vermis regions $(P<.1)$ in preterm infants with brain injury. Regional CBF in preterm infants with moderate-severe brain injury trended lower in the midpons, right cerebellar hemisphere, and dentate nuclei compared with mild brain injury $(P<.1)$. In addition, a significant, lower regional CBF was associated with ventilation, sepsis, and cesarean delivery $(P<.05)$.

CONCLUSIONS: We report early disturbances in global and regional CBF in preterm infants following brain injury. Regional cerebral perfusion alterations were evident in the thalamus and pons, suggesting regional vulnerability of the developing cerebro-cerebellar circuitry.

ABBREVIATIONS: $\mathrm{ASL}=$ arterial spin-labeling; $\mathrm{BI}=$ brain injury; $\mathrm{DLPF}=$ dorsolateral prefrontal; $\mathrm{GA}=$ gestational age; $I \mathrm{O}=$ inferior occipital; $\mathrm{MT}=$ midtemporal; $\mathrm{PM}=$ premotor; $\mathrm{PO}=$ parieto-occipital; $\mathrm{PT}=$ preterm; $\mathrm{Tl} \mathrm{b}=$ blood longitudinal relaxation time

$\mathbf{P}$ remature birth is a major public health concern, with an estimated worldwide incidence of about $9.6 \%$ of all births. ${ }^{1}$ Preterm birth is associated with a high prevalence of brain injury (BI) and life-long neurodevelopmental morbidity, manifesting in up to $50 \%$ of school-age survivors. ${ }^{2,3}$ Overall prematurity-related

Received December 23, 2017; accepted after revision March 23, 2018.

From the Developing Brain Research Program (E.S.M., M.B.-K., J.M., C.L.), Department of Diagnostic Imaging and Radiology; Department of Neurology (T.C.); and Department of Epidemiology and Biostatistics (M.B.J.), Children's Research Institute, Children's National Health System, Washington, DC; and Institute for Biomedical Sciences (M.B.-.K.), George Washington University, Washington, DC.

This work was supported by the Canadian Institutes of Health Research (MOP81116) and the National Institutes of Health (R01 HL116585-01)

Paper previously presented, in part, orally at: Annual Meeting of the Radiological Society of North America, November 22-December 2, 2016; Chicago, Illinois. A fellow research award was granted.

Please address correspondence to Catherine Limperopoulos, PhD, Developing Brain Research Laboratory, Departments of Diagnostic Imaging and Radiology, Children's National Health System, 111 Michigan Ave NW, Washington, DC 20010; e-mail: climpero@childrensnational.org mortality has decreased in recent years; however, adverse neurodevelopment consequences often persist until later in life. ${ }^{4}$ Only a few structural brain injuries can be recognized in the early postnatal period ( $<7-10$ days) by conventional transcranial sonography or MR imaging. ${ }^{5}$ However, most cases of prematurity-related BI lack structural changes; this feature highlights the importance of studying early disturbances in systemic and cerebral hemodynamics that may predispose to such brain injuries. ${ }^{6}$ Risk factors implicated in prematurity-related BI include alteration of cardiovascular autonomic control, immaturity of the cerebral hemodynamic mechanism, disturbed oxygenation, and vascular fragility. ${ }^{7}$ The onset and extent to which cerebral blood flow is disturbed following preterm birth remain poorly understood, in large part

\footnotetext{
-- Indicates open access to non-subscribers at www.ajnr.org

三 Indicates article with supplemental on-line tables.

http://dx.doi.org/10.3174/ajnr.A5669
} 
because of the lack of availability of reliable monitoring techniques that can directly and noninvasively measure CBF.

Several prior studies have assessed cerebral brain perfusion in the neonate using various techniques such as cerebral artery Doppler, near-infrared spectroscopy, PET, and xenon-enhanced CT. ${ }^{8-11}$ These techniques lack anatomic detail, use indirect cerebral perfusion measurements, and/or have a risk of radiation or the need for intravenous contrast. ${ }^{12-14}$ Conversely, in the present study, we used the arterial spin-labeling (ASL) MR imaging technique, which has recently emerged as a promising noninvasive method for direct quantitative assessment of cerebral perfusion in high-risk neonates, including neonates with perinatal stroke ${ }^{15}$ or hypoxic-ischemic encephalopathy, ${ }^{16}$ without radiation risk or the need for intravenous contrast. ${ }^{13,17}$

While several ASL-MR imaging studies have been reported in full-term neonates, ${ }^{13,18-24}$ only 4 studies have performed ASL-MR imaging in the preterm (PT) period (ie, third trimester of ex utero life), all of which included small sample sizes of preterm infants with no structural BI at the time of the MR imaging. ${ }^{12,25-27}$ To date, to our knowledge, no study has examined early $\mathrm{CBF}$ in PT infants during the third trimester of ex utero brain development to better ascertain the impact of early-life BI on cerebral perfusion.

The primary objective of our study was to compare global and regional $\mathrm{CBF}$ in $\mathrm{PT}$ infants with and without $\mathrm{BI}$ on conventional MR imaging during the third trimester of ex utero life using ASL-MR imaging. As a secondary objective, we examined the relationship between regional cerebral and cerebellar perfusion measures and the degree of BI. Last, we investigated clinical risk factors associated with preterm birth and their potential influence on cerebral perfusion.

\section{MATERIALS AND METHODS Subjects}

In the context of a prospective study, we recruited PT infants ( $<1500 \mathrm{~g}$ and gestational age [GA] of 32 weeks or younger) admitted to the Children's National Medical Center in Washington, DC. PT infants with a known or suspected brain malformation, dysmorphic features, or congenital anomalies suggestive of a genetic syndrome, metabolic disorders, chromosomal abnormality, or CNS infection were excluded. PT infants were stratified into those with and without structural BI on conventional MR imaging. We further categorized PT infants by injury severity: 1) mild injury (grade I/II germinal matrix hemorrhage, punctate cerebellar hemorrhage, and/or mild cerebral white matter injury), and 2) moderate-severe injury (grade III germinal matrix hemorrhage, periventricular hemorrhagic infarction, and/or extensive cerebellar hemorrhage). Medical records were reviewed for all subjects. Specific demographic and clinical variables were extracted including birth weight, GA at birth, GA at MR imaging, sex, Apgar score at 1 and 5 minutes; medications such as pressors, diuretics, caffeine, corticosteroids, indomethacin; sedation 48 hours before MR imaging; resuscitation status such as the use of ventilatory support during the hospital stay; intubation in the 48 hours before MR imaging; patent ductus arteriosus ligation; sepsis; and method of delivery. All data were collected in compliance with Health Information Portability and Accountability Act regula- tions and approved by the institutional review board (Children's National Health System). Informed consent was acquired from all infant guardians.

\section{MR Imaging and Arterial Spin-Labeling Acquisition}

PT infants underwent MR imaging on either 1.5T or 3T scanners (Discovery MR 750 and 450, respectively; GE Healthcare, Milwaukee, Wisconsin). PT infants with specific requirements for a temperature-controlled environment $(n=50,64 \%)$ underwent MR imaging studies on a $1.5 \mathrm{~T}$ scanner using an MR imagingcompatible incubator with 1-channel receiver and transmitter coils. All other PT infants $(n=28,36 \%)$ underwent MR imaging studies on a 3T scanner using 8 receiver-only head coils.

Our acquisition protocol included axial 3D pseudocontinuous arterial spin-labeling with a spiral $k$-space trajectory, which was performed with the following scan parameters: TE/TR $=11 / 4300$ $\mathrm{ms}, \mathrm{FOV}=24 \mathrm{~cm}$, matrix size $=512 \times 8$, section thickness $=3$ $\mathrm{mm}$, and scan time $=3: 25$ minutes. Anatomic T2-weighted images were acquired with either axial T2 periodically rotated overlapping parallel lines with enhanced reconstruction (TE/TR = $101.7 / 6313 \mathrm{~ms}$, section thickness $=2 \mathrm{~mm}$ ) and axial single-shot FSE $(\mathrm{TE} / \mathrm{TR}=160 / 1320 \mathrm{~ms}$, section thickness $=2 \mathrm{~mm})$ for a $1.5 \mathrm{~T}$ scanner, or 3D Cube (GE Healthcare) images (TE/TR $=64 / 2500$ $\mathrm{ms}$, section thickness $=1 \mathrm{~mm}$ ) for a $3 \mathrm{~T}$ scanner. Images were reviewed by an experienced pediatric neuroradiologist (J.M) for evidence of BI and structural abnormalities.

Neonates were generally scanned without sedation. Sedation was used on a small subset $(n=10)$ for clinical indications. All PT infants underwent vital signs monitoring throughout the scan.

\section{Data Analysis/ASL Processing}

CBF maps were generated using FuncTool software (GE Healthcare) in milliliters $/ 100 \mathrm{~g} /$ minute. The blood longitudinal relaxation time (T1b) was corrected to 1.7 seconds. ${ }^{12}$ We then created a brain mask of the perfusion map, which was coregistered to anatomic T2-weighted images. Global CBF was calculated from the cerebral perfusion map using FSL software (http://fsl.fmrib. ox.ac.uk/fsl/fslwiki).

The coregistered CBF map and T2-weighted images were used for anatomic delineation and ROI placement to quantify regional CBF. ROIs were manually placed using ITK-SNAP software (Version 3.4.0; www.itksnap.org) and were calculated as an average value from both the left and right cerebral hemispheres for ROIs that did not show bilateral differences on paired $t$ tests at $P<.05$. ROIs were drawn as a small square of $2-3 \mathrm{~mm}$ in the cerebral cortices in the dorsolateral prefrontal (DLPF), premotor (PM), primary motor, parieto-occipital (PO), midtemporal (MT), and inferior occipital (IO) regions. ${ }^{28}$ Thalami, midpons, anterior and posterior vermis, dentate nuclei, and cerebellar hemispheres were also included (Figs 1 and 2). The mean volume of ROIs was 23.7$47.2 \mathrm{~mm}^{3}$ (average, $33.06 \mathrm{~mm}^{3}$ ). The DLPF, PM, primary motor, and PO ROIs were drawn at the level of centrum semiovale and central sulcus. The MT and IO ROIs were drawn at the level of temporal horns of the lateral ventricles. All ROIs were localized by evaluation of the images in 3 orthogonal planes. Intrarater and interrater reliability was assessed via intraclass correlation coefficients on a randomly selected group of $29 \mathrm{PT}$ infants. The mean intraclass cor- 
relation coefficients for intrarater reliability measurements ranged from 0.62 to 0.96 (median, 0.82 ), and for interrater measurements, they ranged from 0.74 to 0.95 (median, 0.90 ).

\section{Statistical Analysis}

Descriptive characteristics of PT infants with and without BI were compared using $t$ tests for normally distributed continuous variables, the Wilcoxon-Mann-Whitney test for nonparametric continuous outcomes, and the $\chi^{2}$ test for categoric outcomes. Associations between GA at birth and GA at MR imaging and all CBF
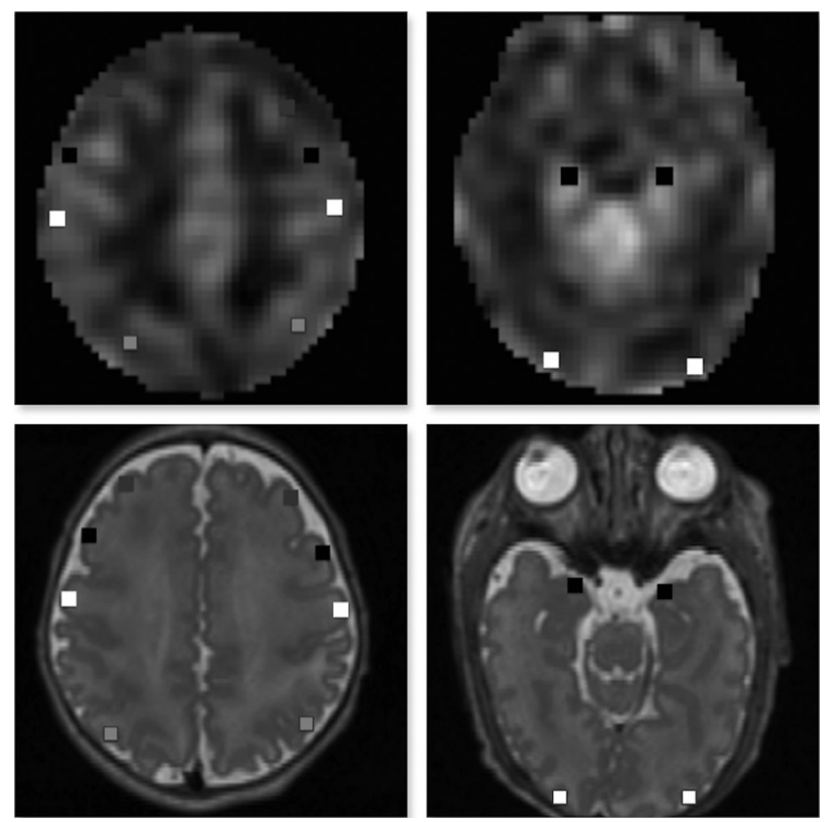

FIG 1. ROIs on axial 3D Cube (GE Healthcare) T2-weighted images (lower panel) coregistered with a corresponding CBF map (upper panel). ROI locations include DLPF, PM, primary motor, and PO cortical regions, respectively, (left panel) and MT and 10 regions (right panel).
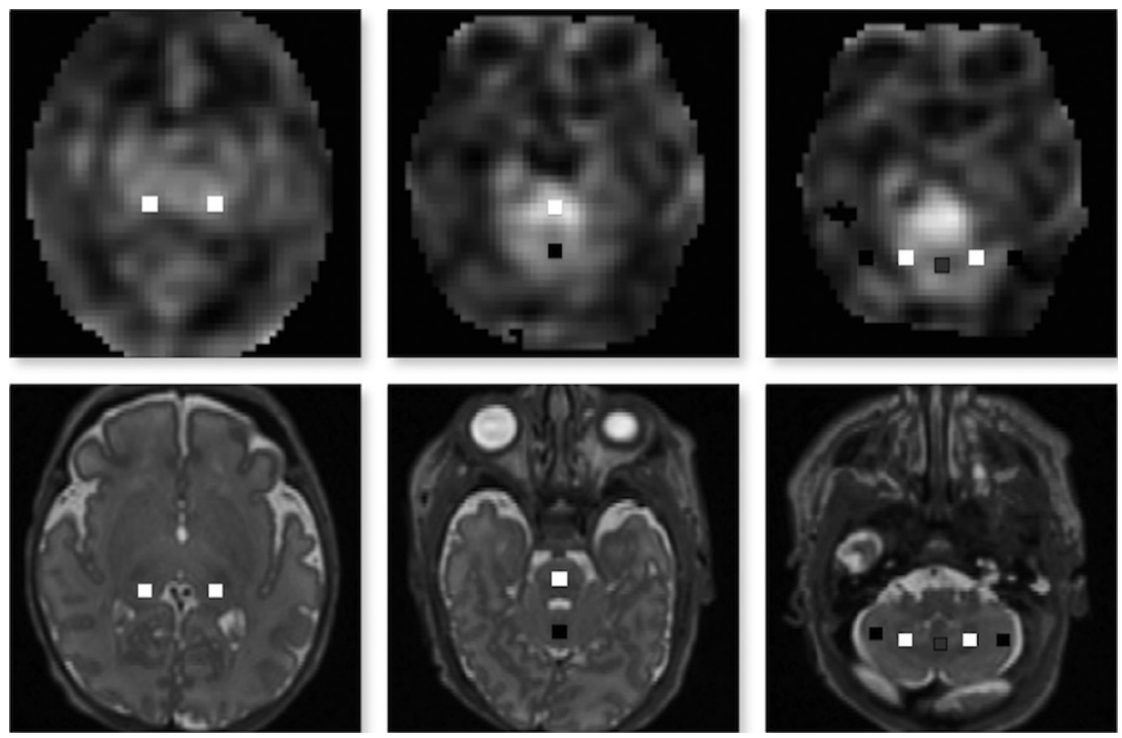

FIG 2. ROIs on axial 3D Cube (GE Healthcare) T2-weighted images (lower panel) coregistered with a corresponding CBF map (upper panel). ROI locations include thalamus regions (left panel), the midpons and anterior vermis (middle panel), and posterior vermis and bilateral dentate and cerebellar hemispheres (right panel). measures were evaluated using generalized linear regression. Differences in CBF by ROIs between PT infants with and without BI and by BI severity were evaluated using ANCOVA, adjusted for GA at birth. Additional adjustment for GA at MR imaging (postmenstrual age) was considered; however, GA at MR imaging was not significantly correlated with any ROIs considered. Finally, generalized linear models were constructed for prespecified medical risk factors and all brain regions, controlling for age at birth, to identify medical factors that may be indicative of region-specific decreased CBF. Categoric risk factors identified in $<10 \%$ of the PT infants were excluded. These included indomethacin and corticosteroid use. Additional analysis controlling for BI status resulted in similar findings. A $P$ value of $<.05$ was considered a significant cutoff.

\section{RESULTS}

\section{Characteristics of the Cohort}

We studied 82 PT infants, of whom 4 were excluded due to technical factors (poor quality T2 or ASL). The remaining $78 \mathrm{PT}$ infants had MR imaging at a mean GA of $33.7 \pm 2.1$ weeks (range, 28.4-37.0 weeks). Of the 78 PT infants, 31 (40\%) had structurally normal MR imaging findings (ie, no BI) and 47 (60\%) had BIs, of which 18 were moderate-severe and 29 were mild. Descriptive characteristics are summarized in Table 1.

\section{Global CBF Measurement of the Cohort}

The adjusted average global CBF showed a borderline significant increase with advancing GA at birth $(P=.05)$, controlling for GA at $\mathrm{MR}$ imaging. However, there was no significant difference in global CBF with GA at MR imaging, controlling for GA at birth. The estimated global CBF was 20.3 (95\% CI, 18.4-22.3) for PT infants without BI and 18.0 (95\% CI, 16.4-19.5) in PT infants with BI, adjusting for GA at birth, indicating that global CBF in PT infants with $\mathrm{BI}$ trended lower than in $\mathrm{PT}$ infants without $\mathrm{BI}(\mathrm{P}=$ .07) (Table 2). 
Table 1: Descriptive characteristics of the cohort $(N=78)$

\begin{tabular}{lccc}
\hline & $\begin{array}{c}\text { PT without BI } \\
(\boldsymbol{n}=31)\end{array}$ & $\begin{array}{c}\text { PT with BI } \\
(\boldsymbol{n}=\mathbf{4 7})\end{array}$ & $\begin{array}{c}\boldsymbol{P} \\
\text { Value }^{\mathrm{a}}\end{array}$ \\
\hline Birth GA (wk) & $28.2 \pm 2.6(22.9-32.0)$ & $26.5 \pm 2.6(23.0-32.6)$ & .007 \\
Birth weight (kg) $^{\mathrm{b}}$ & $1.1 \pm 0.3(0.4-1.5)$ & $0.9 \pm 0.3(0.4-1.5)$ & .04 \\
Days of life at MRI & $41.2 \pm 17.6(10.0-84.0)$ & $49.1 \pm 18.9(15.0-93.0)$ & .07 \\
Apgar score at 1 min $^{\mathrm{c}}$ & $6(4,2-9)$ & $4(4,1-9)$ & .003 \\
Apgar score at 5 min $^{\mathrm{c}}$ & $8(3,4-9)$ & $7(3,3-9)$ & .005 \\
Postmenstrual age at MRI (wk) $^{\mathrm{b}}$ & $34.0 \pm 1.9(30.9-36.9)$ & $33.5 \pm 2.19(28.4-37.0)$ & .37 \\
Weight at MRI (kg) $^{\mathrm{b}}$ & $1.7 \pm 0.4(0.8-2.7)$ & $1.6 \pm 0.5(0.8-3.0)$ & .37 \\
Female (No.) (\%) & $17(54.8)$ & $25(53.2)$ & .89 \\
Cesarean delivery (No.) (\%) $^{\text {(\%) }}$ & $23(74.2)$ & $28(59.6)$ & .18 \\
\hline
\end{tabular}

a $P$ value based on a $t$ test for normally distributed continuous variables, the Wilcoxon-Mann-Whitney test for nonparametric continuous outcomes, and the $\chi^{2}$ test for categoric outcomes.

${ }^{\mathrm{b}}$ Mean (range).

cMedian (interquartile range, range).

\begin{tabular}{|c|c|c|c|}
\hline $\begin{array}{l}\text { Controlling for } \\
\text { GA at Birth }\end{array}$ & $\begin{array}{l}\text { PT without BI } \\
(n=31)\end{array}$ & $\begin{array}{l}\text { PT with BI } \\
(n=47)\end{array}$ & $\begin{array}{c}P \\
\text { Value }\end{array}$ \\
\hline Global CBF & $20.3(18.4-22.3)$ & $18.0(16.4-19.5)$ & .07 \\
\hline DLPF & 16.7 (14.3-19.1) & 14.8 (12.9-16.8) & .24 \\
\hline PM & $21.7(18.9-24.5)$ & 19.4 (17.1-21.6) & .20 \\
\hline Primary motor & 24.7 (21.8-27.7) & $22.3(19.9-24.6)$ & .21 \\
\hline PO & $16.0(13.5-18.5)$ & $14.3(12.3-13.3)$ & .31 \\
\hline MT & $25.8(22.9-29.0)$ & $22.1(19.7-24.7)$ & .07 \\
\hline 10 & $20.9(17.8-24.0)$ & $17.6(15.1-20.1)$ & .11 \\
\hline Rt. thalamus & $35.6(31.1-40.2)$ & $29.5(25.8-33.2)$ & .04 \\
\hline Lt. thalamus & $33.3(28.6-38.1)$ & $27.3(23.5-31.1)$ & .06 \\
\hline Midpons & $48.5(41.6-55.3)$ & $37.4(31.8-43.1)$ & .02 \\
\hline Ant vermis & $34.0(28.2-39.8)$ & $27.3(22.5-32.0)$ & .08 \\
\hline Post vermis & $32.4(25.5-39.2)$ & $27.8(22.3-33.2)$ & .31 \\
\hline $\begin{array}{l}\text { Rt. cerebellar } \\
\text { hemisphere }\end{array}$ & $21.0(16.5-25.5)$ & $19.0(15.4-22.6)$ & .50 \\
\hline $\begin{array}{l}\text { Lt. cerebellar } \\
\text { hemisphere }\end{array}$ & $22.8(17.5-28.1)$ & $22.0(17.7-26.3)$ & .81 \\
\hline Dentate & $30.6(24.2-37.0)$ & $29.0(22.5-35.4)$ & .72 \\
\hline
\end{tabular}

Note:-Rt. Indicates right; Lt., left; Ant, anterior; Post, posterior.

a $P$ value $<.05$ was considered significant. Data are means ( $95 \%$ confidence intervals).

ventilation, intubation in the 48 hours before MR imaging, and cesarean delivery were associated with lower global or regional $\mathrm{CBF}$. However, pressor use was associated with higher CBF. Other risk factors explored were patent ductus arteriosus ligation, diuretic or caffeine use before MR imaging, and sedation 48 hours before MR imaging (On-line Table 3), though no significant associations were noted. Additional analysis controlling for BI status resulted in similar findings.

\section{Influence of 1.5T versus 3T MR Imaging on CBF Measures}

We adjusted our analyses for scanner type (1.5T versus $3 \mathrm{~T})$ and found no significant differences in global or regional CBF values for our cerebral regions or the vermis or dentate nuclei. Only cerebellar hemispheric CBF was significantly higher at $1.5 \mathrm{~T}$ compared with $3 \mathrm{~T}(P=.03)$.

\section{DISCUSSION}

In this prospective observational study, we report, for the first time, early disturbances in cerebral perfusion between PT infants with and without structural BI during the third trimester of ex utero development. We demonstrate that global CBF trended slightly lower in PT infants with BI compared with those without.
Regional CBF was significantly lower in the right thalamus and midpons and trended lower in the MT, left thalamus, and anterior vermis in PT infants with $\mathrm{BI}$, suggesting regional vulnerability of the developing cerebro-cerebellar circuitry. These results collectively emphasize that perfusion effects in PT infants with BI and specifically moderate-severe injury are directed lower compared with those without BI. Finally, we reveal an association between lower regional CBF and the presence of sepsis, use of ventilation, intubation in the last 48 hours before the MR imaging, and cesarean delivery, after controlling for GA at birth.

Available data on cerebral perfusion using ASL-MR imaging in the neonatal period are limited, particularly available data with MR imaging studies performed during the preterm period (ie, third trimester of ex utero life) or those with prematurity-related brain injury. To date, most studies have been performed either in full-term infants or PT infants at term-equivalent age. ${ }^{13,17-24}$ Quantitative data on CBF in PT infants during the third trimester of development are scarce. To the best of our knowledge, only 4 studies have performed ASL-MR imaging at preterm age. ${ }^{12,25-27}$ Varela et $\mathrm{al}^{25}$ scanned $<10$ PT infants without BI to quantify the ASL parameters and techniques. De Vis et al ${ }^{12}$ scanned $6 \mathrm{PT}$ infants, looking for cerebral perfusion changes with brain maturation. In another study by the same authors, ${ }^{27}$ scanning of $18 \mathrm{PT}$ infants was performed to assess hematocrit variability in the $\mathrm{T} 1 \mathrm{~b}$ and ASL measurements. Ouyang et $\mathrm{al}^{26}$ reported higher global $\mathrm{CBF}$ and heterogeneous increases in regional CBF during the third trimester in $17 \mathrm{PT}$ infants. Our data are in keeping with these findings; however, our study is the first to characterize quantitative regional CBF in PT infants with BI.

The mechanisms underlying disturbed CBF in PT infants are undoubtedly complex and likely multifactorial. In part, they may be related to the impact of PT birth on the alteration of cardiovascular autonomic control, which can manifest as variability in heart rate and blood pressure. ${ }^{7}$ Another potential mechanism may relate to immature cerebral hemodynamics, which increases the risk for cerebral hemorrhage and hypoxic-ischemic injury, especially in extremely premature infants. ${ }^{7,28}$ Increases in physiologic stress and metabolic demand, either in utero or during the early extrauterine life, may exceed the ability of the increase in cerebral blood flow. ${ }^{7}$

Our finding of decreased CBF in PT infants with BI corroborates a previous study by Lin et al, ${ }^{29}$ using near-infrared spectroscopy and diffuse correlation spectroscopy imaging. However, ASL-MR imaging has an advantage over the previous method because it is a direct quantitative technique for assessing cerebral perfusion. Furthermore, it can be combined with other MR imaging techniques (spectroscopy, diffusion, and functional) to give a more comprehensive understanding of the pathophysiologic consequences of early hemodynamic disturbances. ${ }^{14}$

The decrease in regional CBF in the thalami, midpons, anterior vermis, and dentate nuclei in PT infants with BI suggests a 
regional vulnerability of the developing cerebro-cerebellar circuitry. This circuitry includes multiple complex closed-loop circuits between the cerebral cortical regions and the cerebellum that control movement, language, and social processing. ${ }^{30}$ The pivotal structures for this anatomic connection are located within the thalamus and brain stem regions, which represent areas with the highest perfusion during this critical preterm period of brain development. Limperopoulos et $\mathrm{al}^{31}$ reported a significant association between cerebellar injury in PT infants and impairment of regional volumetric growth in the contralateral cerebrum. ArcaDíaz et $\mathrm{al}^{32}$ reported that $\mathrm{ADC}$ values in the brain stem and cerebellum can predict the outcomes of neonates with hypoxicischemic encephalopathy; this finding further emphasizes the importance of the cerebro-cerebellar connection.

Our analysis of medical risk factors and CBF was primarily exploratory. The potential effects of ventilation or intubation status on CBF are complex. ${ }^{33}$ Other studies using near-infrared spectroscopy or intravenous ${ }^{133} \mathrm{Xe}$ reported a decrease in CBF in ventilated PT infants, ${ }^{33}$ which is supported by our data. Most of the ventilated $\mathrm{PT}$ infants were on sedative medication at some point during their neonatal intensive care unit stay. It has been shown by van Alfen-van der Velden et $\mathrm{al}^{34}$ that morphine is associated with increased cerebral blood volume, and midazolam, with a decrease in CBF velocity in ventilated PT infants. In our study, we examined the effect of sedative medication used up to 48 hours before MR imaging and found that there were no significant differences in CBF between PT infants who were sedated and those who were not sedated. This finding could be partly related to the small subset of PT infants receiving sedative medications in our cohort $(n=10)$.

There are several studies that report $\mathrm{CBF} /$ cerebral oxygenation differences according to the mode of delivery during the neonatal period. ${ }^{35}$ Our data further support the notion that cesarean delivery may play a role in cerebral perfusion changes, with decreases in regional CBF noted. The effect of early-onset neonatal sepsis on CBF is complex and depends mainly on the changes in the cerebral autoregulatory mechanism. ${ }^{36}$ Many of our neonates who had sepsis during their hospital stay have shown a decrease in regional CBF. Our data also demonstrate an increase in regional CBF in PT infants who had vasopressor medication during their first week of life before MR imaging, which further supports the finding that low-dose dopamine can result in a temporary elevation in CBF in PT infants. ${ }^{37}$

Our study has several strengths: the largest sample size of PT infants scanned at preterm age of the third trimester of development using ASL-MR imaging to date, the inclusion of PT infants with various degrees of structural BI, and the examination of a variety of clinical factors that may influence perfusion. Acknowledging that ASL has been shown to change with GA, we controlled for GA at birth in our analysis. ${ }^{12}$

Our study also has some limitations, one of which is the use of generic T1b instead of a subject-specific T1 relaxation of the blood, which can be affected by hematocrit level. ${ }^{38}$ The manual placement of the ROIs is another limitation because it is raterdependent. However, we achieved good inter- and intrarater reliability measurements. The use of sedation at MR imaging in 10 PT infants may be another confounder to the study; however, comparison analyses between PT infants with and without sedation demonstrated no statistically significant differences in global or regional $\mathrm{CBF}$.

Furthermore, the use of different MR imaging field strengths (1.5T and $3 \mathrm{~T})$ is another potential limitation. However, the 2 groups (those studied on 1.5T versus 3T) may not be similar because those PT infants who needed an MR imaging incubator and a temperature-controlled environment due to their medical status were studied on the $1.5 \mathrm{~T}$ scanner. Our results according to BI status were consistent across both scanners. In other words, the CBF measures in PT infants with BI were consistently lower compared with the PT infants without BI, and this finding is likely not due to scanner differences. Nevertheless, the best way to compare CBF measurement differences between a $1.5 \mathrm{~T}$ versus $3 \mathrm{~T}$ scanner would be to compare measurements in the same infants acquired on both scanners on the same day back to back. However, this was not possible in our study, given the acuity of illness of our cohort. Future work on the impact of MR imaging field strength on cerebral and cerebellar CBF measures is warranted.

Finally, the extent to which these early regional CBF disturbances impair subsequent cerebro-cerebellar development and connectivity and functional outcomes in survivors of preterm birth is an intriguing question that deserves further exploration.

\section{CONCLUSIONS}

We demonstrate that ASL provides a useful noninvasive tool for identifying early cerebral perfusion abnormalities in PT infants with BI. The ability to directly and noninvasively monitor CBF with ASL-MR imaging in the early postnatal period, when PT infants are at greatest risk for BI, is promising and may assist in identifying candidates for future therapeutic targets and measuring treatment effectiveness.

\section{ACKNOWLEDGMENTS}

We are thankful to all the families that participated in this study. We would like to thank Ms Caitlyn Loucas for her assistance in recruitment (Ms Loucas has no financial disclosure and no conflict of interest to report).

Disclosures: Marni B. Jacobs—RELATED: Grant: National Institutes of Health, Comments: work supported by the Clinical and Translational Science Institute Center Grant awarded to Children's National as part of the Biostatistics, Epidemiology, and Research Design Core*; UNRELATED: Consultancy: PATH, Inova Children's Hospital, Comments: consulting fees paid for scientific merit review (PATH) and statistical analysis (Inova); Grants/Grants Pending: Jain Foundation, ATyr Pharma, Department of Defense, Comments: biostatistician on grants related to neuromuscular disorders*; Travel/Accommodations/Meeting Expenses Unrelated to Activities Listed: Treat-NMD, Comments: Travel paid for scientific review panel for neuromuscular grant submissions. Catherine Limperopoulos—RELATED: Grant: National Institutes of Health RO1HL116585-01, Canadian Institutes of Health Research MOP-81116.* *Money paid to the institution.

\section{REFERENCES}

1. Beck S, Wojdyla D, Say L, et al. The worldwide incidence of preterm birth: a systematic review of maternal mortality and morbidity. Bull World Health Organ 2010;88:31-38 CrossRef Medline

2. Hamilton BE1, Miniño AM, Martin JA, et al. Annual summary of vital statistics: 2005. Pediatrics 2007;119:345-60 CrossRef Medline

3. Ment LR, Vohr BR. Preterm birth and the developing brain. Lancet Neurol 2008;7:378-79 CrossRef Medline 
4. Saigal S, Doyle LW. An overview of mortality and sequelae of preterm birth from infancy to adulthood. Lancet 2008;371:261-69 CrossRef Medline

5. Volpe JJ. Intraventricular hemorrhage in the premature infant: current concepts, Part I. Ann Neurol 1989;25:3-11 CrossRef Medline

6. Shalak L, Perlman JM. Hemorrhagic-ischemic cerebral injury in the preterm infant: current concepts. Clin Perinatol 2002;29:745-63 CrossRef Medline

7. Fyfe KL, Yiallourou SR, Wong FY, et al. The development of cardiovascular and cerebral vascular control in preterm infants. Sleep Med Rev 2014;18:299-310 CrossRef Medline

8. Shi $Y$, Jin $R$, Zhao J, et al. Brain positron emission tomography in preterm and term newborn infants. Early Hum Dev 2009;85:429-32 CrossRef Medline

9. Levene MI, Fenton AC, Evans DH, et al. Severe birth asphyxia and abnormal cerebral blood-flow velocity. Dev Med Child Neurol 1989; 31:427-34 Medline

10. Peeples ES, Mehic E, Mourad PD, et al. Fast Doppler as a novel bedside measure of cerebral perfusion in preterm infants. Pediatr Res 2016;79:333-38 CrossRef Medline

11. Marin T, Moore J. Understanding near-infrared spectroscopy. $A d v$ Neonatal Care 2011;11:382-88 CrossRef Medline

12. De Vis JB, Petersen ET, De Vries LS, et al. Regional changes in brain perfusion during brain maturation measured non-invasively with arterial spin labeling MRI in neonates. Eur J Radiol 2013;82:538-43 CrossRef Medline

13. Massaro AN, Bouyssi-Kobar M, Chang T, et al. Brain perfusion in encephalopathic newborns after therapeutic hypothermia. AJNR Am J Neuroradiol 2013;34:1649-55 CrossRef Medline

14. Calamante F, Thomas DL, Pell GS, et al. Measuring cerebral blood flow using magnetic resonance imaging techniques. J Cereb Blood Flow Metab 1999;19:701-35 CrossRef Medline

15. Watson CG, Dehaes M, Gagoski BA, et al. Arterial spin labeling perfusion magnetic resonance imaging performed in acute perinatal stroke reveals hyperperfusion associated with ischemic injury. Stroke 2016;47:1514-19 CrossRef Medline

16. Licht DJ, Wang J, Silvestre DW, et al. Preoperative cerebral blood flow is diminished in neonates with severe congenital heart defects. J Thorac Cardiovasc Surg 2004;128:841-49 CrossRef Medline

17. Deibler AR, Pollock JM, Kraft RA, et al. Arterial spin-labeling in routine clinical practice, Part 1: technique and artifacts. AJNR Am J Neuroradiol 2008;29:1228-34 CrossRef Medline

18. De Vis JB, Hendrikse J, Petersen ET, et al. Arterial spin-labelling perfusion MRI and outcome in neonates with hypoxic-ischemic encephalopathy. Eur Radiol 2015;25:113-21 CrossRef Medline

19. Nagaraj UD, Evangelou IE, Donofrio MT, et al. Impaired global and regional cerebral perfusion in newborns with complex congenital heart disease. J Pediatr 2015;167:1018-24 CrossRef Medline

20. Wintermark P, Hansen A, Warfield SK, et al. Near-infrared spectroscopy versus magnetic resonance imaging to study brain perfusion in newborns with hypoxic-ischemic encephalopathy treated with hypothermia. Neuroimage 2014;85:287-93 CrossRef Medline

21. Wintermark $\mathrm{P}$, Hansen A, Gregas MC, et al. Brain perfusion in asphyxiated newborns treated with therapeutic hypothermia. AJNR Am J Neuroradiol 2011;32:2023-29 CrossRef Medline

22. Tortora D, Mattei PA, Navarra R, et al. Prematurity and brain perfusion: arterial spin labeling MRI. Neuroimage Clin 2017;15: 401-07 CrossRef Medline
23. Miranda MJ, Olofsson K, Sidaros K. Noninvasive measurements of regional cerebral perfusion in preterm and term neonates by magnetic resonance arterial spin labeling. Pediatr Res 2006;60:359-63 CrossRef Medline

24. Bouyssi-Kobar M, Murnick J, Brossard-Racine M, et al. Altered cerebral perfusion in infants born preterm compared with infants born full term. J Pediatr 2018;193:54-61.e2 CrossRef Medline

25. Varela M, Petersen ET, Golay X, et al. Cerebral blood flow measurements in infants using look-locker arterial spin labeling. J Magn Reson Imaging 2015;41:1591-600 CrossRef Medline

26. Ouyang M, Liu P, Jeon T, et al. Heterogeneous increases of regional cerebral blood flow during preterm brain development: preliminary assessment with pseudo-continuous arterial spin labeled perfusion MRI. Neuroimage 2017;147:233-42 CrossRef Medline

27. De Vis JB, Hendrikse J, Groenendaal F, et al. Impact of neonate haematocrit variability on the longitudinal relaxation time of blood: implications for arterial spin labelling MRI. Neuroimage Clin 2014;4:517-25 CrossRef Medline

28. Brew N, Walker D, Wong FY. Cerebral vascular regulation and brain injury in preterm infants. Am J Physiol Regul Integr Comp Physiol 2014;306:R773-86 CrossRef Medline

29. Lin PY, Hagan K, Fenoglio A, et al. Reduced cerebral blood flow and oxygen metabolism in extremely preterm neonates with low-grade germinal matrix-intraventricular hemorrhage. Sci Rep 2016;6:25903 CrossRef Medline

30. D'Mello AM, Stoodley CJ. Cerebro-cerebellar circuits in autism spectrum disorder. Front Neurosci 2015;9:408 CrossRef Medline

31. Limperopoulos C, Chilingaryan G, Guizard N, et al. Cerebellar injury in the premature infant is associated with impaired growth of specific cerebral regions. Pediatr Res 2010;68:145-50 CrossRef Medline

32. Arca-Díaz G, Re TJ, Drottar M, et al. Can cerebellar and brainstem apparent diffusion coefficient (ADC) values predict neuromotor outcome in term neonates with hypoxic-ischemic encephalopathy (HIE) treated with hypothermia? PLoS One 2017;12:e0178510 CrossRef Medline

33. Baenziger O, Jaggi JL, Mueller AC, et al. Cerebral blood flow in preterm infants affected by sex, mechanical ventilation, and intrauterine growth. Pediatr Neurol 1994;11:319-24 CrossRef Medline

34. van Alfen-van der Velden AA, Hopman JC, Klaessens JH, et al. Effects of midazolam and morphine on cerebral oxygenation and hemodynamics in ventilated premature infants. Biol Neonate 2006;90:197202 CrossRef Medline

35. Pichler G, Schmölzer GM, Urlesberger B. Cerebral tissue oxygenation during immediate neonatal transition and resuscitation. Front Pediatr 2017;5:29 CrossRef Medline

36. Basu S, Dewangan S, Chandra Shukla R, et al. Cerebral blood flow velocity in early-onset neonatal sepsis and its clinical significance. Eur J Pediatr 2012;171:901-09 CrossRef Medline

37. Seri I, Rudas G, Bors Z, et al. Effects of low-dose dopamine infusion on cardiovascular and renal functions, cerebral blood flow, and plasma catecholamine levels in sick preterm neonates. Pediatr Res 1993;34:742-49 CrossRef Medline

38. Borogovac A, Asllani I. Arterial spin labeling (ASL) fMRI: advantages, theoretical constrains and experimental challenges in neurosciences. Int J Biomed Imaging 2012;2012:818456 CrossRef Medline 